\title{
Pathogenicity of severe fever with thrombocytopenia syndrome virus in mice regulated in type I interferon signaling
}

\section{Severe fever with thrombocytopenia and type I interferon}

Seok-Chan Park', Jun Young Park',2, Jin Young Choi', Sung-Geun Lee², Seong Kug Eo 1,2, Jae-Ku Oem',

Dong-Seob Tark ${ }^{2}$, Myungjo You', Do-Hyeon Yu ${ }^{3}$, Joon-Seok Chae ${ }^{4}$ and Bumseok Kim ${ }^{1,2^{*}}$ (D)

\begin{abstract}
Severe fever with thrombocytopenia syndrome (SFTS) is an emerging zoonotic disease, which causes high fever, thrombocytopenia, and death in humans and animals in East Asian countries. The pathogenicity of SFTS virus (SFTS V) remains unclear. We intraperitoneally infected three groups of mice: wild-type (WT), mice treated with blocking anti-type I interferon (IFN)-a receptor antibody (IFNAR Ab), and IFNAR knockout (IFNAR ${ }^{-1-}$ ) mice, with four doses of SFTSV $\left(\mathrm{KH1}, 5 \times 10^{5}\right.$ to $\left.5 \times 10^{2} \mathrm{FAID}_{50}\right)$. The WT mice survived all SFTSV infective doses. The IFNAR Ab mice died within 7 days post-infection (dpi) with all doses of SFTSV except that the mice were infected with $5 \times 10^{2}$ FAID $_{50}$ SFTSV. The IFNAR ${ }^{-1-}$ mice died after infection with all doses of SFTSV within four dpi. No SFTSV infection caused hyperthermia in any mice, whereas all the dead mice showed hypothermia and weight loss. In the WT mice, SFTSV RNA was detected in the eyes, oral swabs, urine, and feces at $5 \mathrm{dpi}$. Similar patterns were observed in the IFNAR Ab and IFNAR ${ }^{-1-}$ mice after $3 \mathrm{dpi}$, but not in feces. The IFNAR Ab mice showed viral shedding until $7 \mathrm{dpi}$. The SFTSV RNA loads were higher in organs of the IFNAR ${ }^{-/-}$mice compared to the other groups. Histopathologically, coagulation necrosis and mononuclear inflammatory cell infiltration in the liver and white pulp atrophy in the spleen were seen as the main lesions in the IFN signaling lacking mice. Immunohistochemically, SFTSV antigens were mainly detected in the marginal zone of the white pulp of the spleen in all groups of mice, but more viral antigens were observed in the spleen of the IFNAR ${ }^{-/-}$mice. Collectively, the IFN signaling-deficient mice were highly susceptible to SFTSV and more viral burden could be demonstrated in various excreta and organs of the mice when IFN signaling was inhibited.
\end{abstract}

Keywords: Severe fever with thrombocytopenia syndrome, Type I interferon, Mice, Pathogenicity

\footnotetext{
*Correspondence: bskims@jbnu.ac.kr

'College of Veterinary Medicine, Jeonbuk National University, Iksan 54596, Republic of Korea

${ }^{2}$ Korea Zoonosis Research Institute, Jeonbuk National University, Iksan 54531, Republic of Korea

Full list of author information is available at the end of the article
}

(C) The Author(s). 2020 Open Access This article is licensed under a Creative Commons Attribution 4.0 International License, which permits use, sharing, adaptation, distribution and reproduction in any medium or format, as long as you give appropriate credit to the original author(s) and the source, provide a link to the Creative Commons licence, and indicate if changes were made. The images or other third party material in this article are included in the article's Creative Commons licence, unless indicated otherwise in a credit line to the material. If material is not included in the article's Creative Commons licence and your intended use is not permitted by statutory regulation or exceeds the permitted use, you will need to obtain permission directly from the copyright holder. To view a copy of this licence, visit http://creativecommons.org/licenses/by/4.0/. The Creative Commons Public Domain Dedication waiver (http://creativecommons.org/publicdomain/zero/1.0/) applies to the data made available in this article, unless otherwise stated in a credit line to the data. 


\section{Introduction}

Severe fever with thrombocytopenia syndrome (SFTS) is an emerging viral zoonotic disease, caused by Dabie Bandavirus [former SFTS virus (SFTSV)]. SFTSV is a tick-borne virus belonging to the Genus Bandavirus (former Huaiyangshan Banyangvirus), Family Phenuiviridae. SFTSV causes high fever, thrombocytopenia, and leukocytopenia, followed by multi-organ dysfunction (MOD) and death in humans in East Asian countries [1]. Since SFTSV was first identified in China in 2010, SFTS cases have been identified in China, Japan, South Korea, Vietnam, and Taiwan [2]. The fatality rate of SFTS is high $(6-32 \%)$ but more specific or effective treatments or vaccines have not been developed yet [3]. Thus, SFTS is listed in the World Health Organization Prioritized Pathogens, which pose major public health risks and further research and development are needed [4].

To study the pathogenesis of SFTSV and make therapeutics and vaccines, animal models with human-like symptoms are essential. At present, rhesus macaque monkeys, which had shown symptoms similar to humans in other viral diseases, did not show human-like symptoms when infected with SFTSV [5]. Old ferrets and cats have been shown to exhibit human-like symptoms when infected with SFTSV, but many immunerelated functional studies cannot be performed in these animals. Therefore, they have limitations as animal models compared to mice $[6,7]$.

Interferons (IFNs) are key effectors of viral infection in innate and adaptive immune systems and are categorized into three groups (type I, II, and III) [8]. Type I IFNs bind to a common IFN- $\alpha / \beta$ receptor (IFNAR), which initiates a signaling cascade that induces the expression of thousands of antiviral effector function genes. Previous studies showed that type I IFN response is essential for SFTSV infection [9-11]. Several studies have been conducted using mice as animal models of SFTSV. The studies reported that no clinical symptoms or deaths occurred in mice with normal immune responses infected with SFTSV. Only type I interferon (IFN)-deficient mouse models, newborn mice, mitomycin-treated mice, and STAT2knockout (KO) hamsters are available as models for the fatal illness caused by SFTSV infection [10, 12]. IFNAR KO (IFNAR ${ }^{-/-}$) mice have been previously used as small animal models for SFTSV infection and other emerging viruses, such as Zika virus (ZIKV) and Rift valley fever virus [11, 13-15]. However, IFNAR $^{-/-}$mice models have particular use because they lack a key component of antiviral immunity.

Thus, we utilized the IFNAR antibody (Mab, MAR1$5 \mathrm{~A} 3)$ to inhibit the IFN signaling temporarily, which allowed the mice with intact IFNAR, a key component of antiviral immunity, to be infected with SFTSV.

\section{Materials and methods}

\section{Viruses and cells}

The Korean SFTSV strain KH1 (GenBank accession no. MH491547, MH491548.1, MH491549.1) was kindly provided by Dr. Joon-Seok Chae [16]. This virus was passaged five times on monolayers of Vero E6 cells in DMEM containing 5\% fetal bovine serum (FBS) with antibiotics (penicillin; $100 \mathrm{U} / \mathrm{ml}$, streptomycin; $100 \mu \mathrm{g} / \mathrm{ml}$ ). The virus infectivity titers were determined through a fluorescence active infectious dose $\left(\right.$ FAID $\left._{50}\right)$ assay.

\section{Animal infection and sample collection}

Six-week-old female C57BL/6 mice (WT, Samtako, Kyoung Gi-do, Korea) and 6-week-old type 1 IFN receptor knockout (IFNAR ${ }^{--}$) female mice were used in this study. To study the correlation between immunologic competence and the pathogenicity of SFTSV, MAR15A3 (mouse anti-mouse IFNAR, IgG1) monoclonal antibody (MAb) was administered as an intraperitoneal (IP) injection of $100 \mu \mathrm{g}$ per mouse 1 day before SFTSV infection and 2 days post-infection (dpi) to the C57BL/6 mice (IFNAR Ab mice). The IFNAR ${ }^{-/-}$mice, purchased from B\&K Universal (Hull, UK), were backcrossed onto C57BL/6 mice for at least 10 generations. The Mice were inoculated intraperitoneally (i.p.) with $5 \times 10^{5}$ to $5 \times 10^{2}$ FAID $_{50}$ in a volume of $200 \mu \mathrm{L}$ of phosphatebuffered saline (PBS). Body temperature was obtained using the rectal probes. Blood samples were collected from the retro-orbital venous plexus and analyzed with an automatic blood cell counter (Exigo-Vet., Boule Medical AB Inc., Stockholm, Sweden). The sera were frozen at $-80{ }^{\circ} \mathrm{C}$ until further analysis. Eye and oral swabs, feces, and urine samples were placed in $200 \mu \mathrm{L}$ of PBS and stored at $-80{ }^{\circ} \mathrm{C}$. The SFTSV infected mice were euthanized and the organs were harvested aseptically. All SFTSV infection studies were performed in an animal biosafety level 3 laboratory. All animal experiments followed the requirements of the Animal Care and Ethics Committees of Jeonbuk National University (approval number: JBNU 2019-002).

\section{Detection of SFTSV RNA by reverse transcription- polymerase chain reaction}

Total RNA was isolated by using Hybrid- $\mathrm{R}^{\mathrm{TM}}$ (GeneAll, Seoul, Korea). The RNA was reverse transcribed using a ReverTra Ace qPCR RT Master Mix (TOYOBO, Osaka, Japan) to generate cDNA. The viral copy numbers were determined by real-time PCR (RT-PCR) with an L segment-based SFTSV-specific primer. The forward primer sequence was SFTSV-L-F: AACATCCTGG ACCTTGCATC and the reverse primer sequence was SFTSV-L-R: CAATGTGGCCATCTTCTCCA [17]. Copy numbers were determined by comparison to a standard control. RT-PCR was performed using CFX96 Real-time 
PCR (Bio-Rad Laboratories, Hercules, CA) with qPCR SyGreen Mix (PCRbiosystems, Seoul, Korea).

\section{Histopathology and immunohistochemistry}

In the $5 \times 10^{2}$ FAID $_{50}$ SFTSV infection experiment, four mice from each group were necropsied $1,3,7,12$, and $17 \mathrm{dpi}$, and samples of the brain, lung, liver, spleen, kidney, small intestine (s. intestine), and large intestine (l. intestine) were obtained for histopathologic and immunohistochemical examination and SFTSV genome quantification by RT-PCR. The collected organ tissues were fixed with $10 \%$ neutral phosphate-buffered formalin and processed and embedded in paraffin according to standard procedures. The embedded tissues were sectioned to $6 \mu \mathrm{m}$ thicknesses using a microtome (HM-340E; Thermo Fisher Scientific Inc., Waltham, MA, USA) and placed on slides. The sectioned tissues were stained with hematoxylin and eosin $(\mathrm{H} \& \mathrm{E})$ according to a standard protocol. To detect the viral antigen by immunohistochemistry, a mouse monoclonal antibody against SFTSV $\mathrm{N}$ protein (kindly provided by Dr. Jun-Gu Choi, Animal and Plant Quarantine Agency, Korea) was used as the primary antibody.

\section{Statistical analysis}

Unless otherwise indicated, comparisons between the groups in the in vivo experiments were performed by a 2-tailed Mann-Whitney test or one-way ANOVA followed by Tukey's multiple comparison test. A $p$-value of $<0.05$ was considered statistically significant. Statistical analyses were performed by GraphPad Prism version 8.00 .

\section{Results}

Susceptibility to SFTSV in mice deficient in type I interferon signaling

Three groups of mice were intraperitoneally infected (WT, IFNAR Ab, and IFNAR ${ }^{-1-}$ mice) with four doses of SFTSV (KH1, $5 \times 10^{5}$ to $5 \times 10^{2}$ FAID $_{50}$ ). The WT mice showed no mortality from any dose of SFTSV (Fig. 1a). In mice infected with $5 \times 10^{5}, 5 \times$ $10^{4}$, and $5 \times 10^{3}$ FAID $_{50}$ SFTSV, the IFNAR Ab mice showed $100 \%$ mortality 4,5 , and $7 \mathrm{dpi}$, respectively, and showed steady weight loss until just before death. However, in the $5 \times 10^{2}$ FAID $_{50}$ SFTSV infection experiment, the IFNAR Ab mice did not succumb to SFTSV and recovered the lost weight after 7 dpi (Fig. 1b). This finding in the IFNAR Ab mice given a low
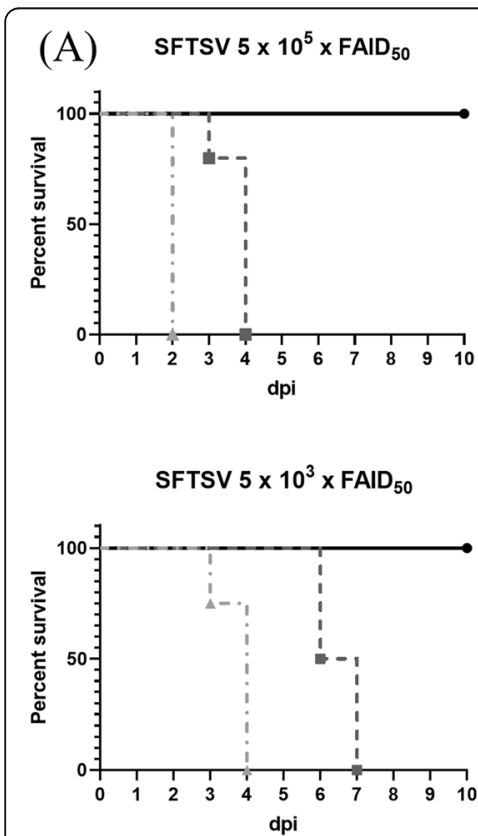

SFTSV $5 \times 10^{4} \times$ FAID $_{50}$

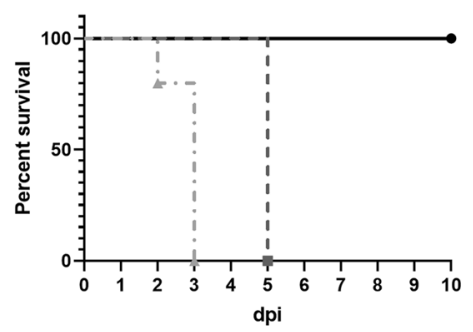

SFTSV $5 \times 10^{2} \times$ FAID $_{50}$

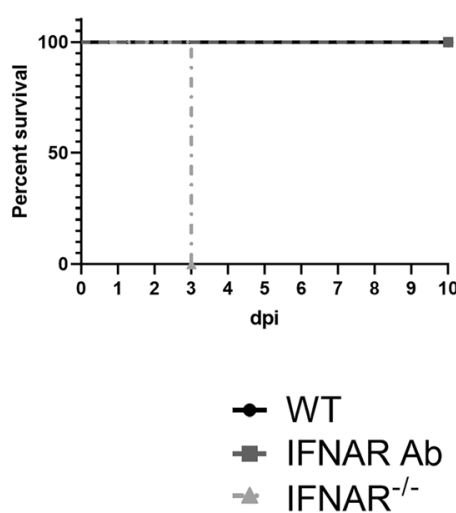

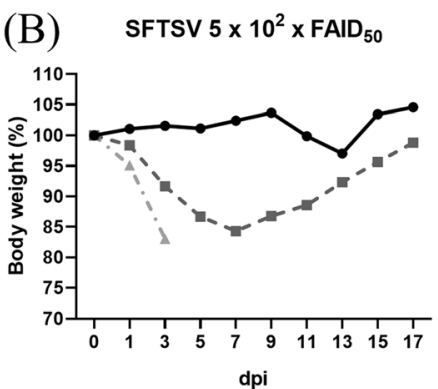

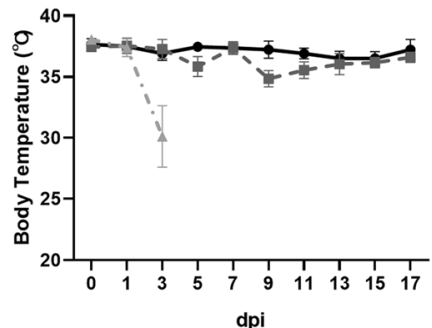

Fivival rate, weight loss, and body temperature of mice with different type I interferon signaling after SFTSV challenge. Three groups of mice, C57 BL/6 (WT), mice treated with blocking anti-type I interferon-a receptor antibody (IFNAR Ab), and IFNAR knockout (IFNAR ${ }^{-}$) mice, were intraperitoneally infected with four doses of SFTSV $\left(\mathrm{KH} 1,5 \times 10^{5}-5 \times 10^{2} \mathrm{FAID}_{50}\right)$. a Survival rates, b body weight $(\%)$, and body temperature $\left({ }^{\circ} \mathrm{C}\right)$ were analyzed 
dose SFTSV infection might be due to the half-life of IFNAR Ab, which is 5.2 days. The antibody was injected 1 day before infection and 2 dpi [18]. The IFNAR $^{-1-}$ mice succumbed to SFTSV regardless of the SFTSV dose $\left(5 \times 10^{5}\right.$ to $5 \times 10^{2}$ FAID $\left._{50}\right)$ within 4 dpi. No SFTSV-infected mice had hyperthermia (Fig. $1 b)$, whereas all the dead mice showed temperature reduction, ruffled fur, anorexia, depression, gastrointestinal symptoms, and loss of weight after virus infection. To study the pathogenesis of SFTSV and the potential role of IFNAR Ab mice as an animal model for SFTSV, 20 mice of each group were inoculated with $5 \times 10^{2}$ FAID $_{50}$ SFTSV. The hematologic changes were observed and viral burden determined.
Hematologic parameters

To evaluate the hematologic changes in the SFTSVinfected mice, blood samples were collected by retroorbital plexus puncture every 2 days and complete blood counts were performed. White blood cell (WBC) counts in the WT mice remained within the reference range $(2600-10,100 / \mu \mathrm{L})$, but the WBC count in the IFNAR Ab mice increased slightly from 4 to $10 \mathrm{dpi}$ and recovered after 12 dpi (Fig. 2a). Severe thrombocytopenia was not detected in any mice after SFTSV infection (Fig. 2b). A decreasing pattern of RBCs and hematocrit levels was observed in both groups until $12 \mathrm{dpi}$ and the levels were significantly lower in the IFNAR Ab mice compared to the WT mice from 4 to $10 \mathrm{dpi}$ (Fig. 2c, d).

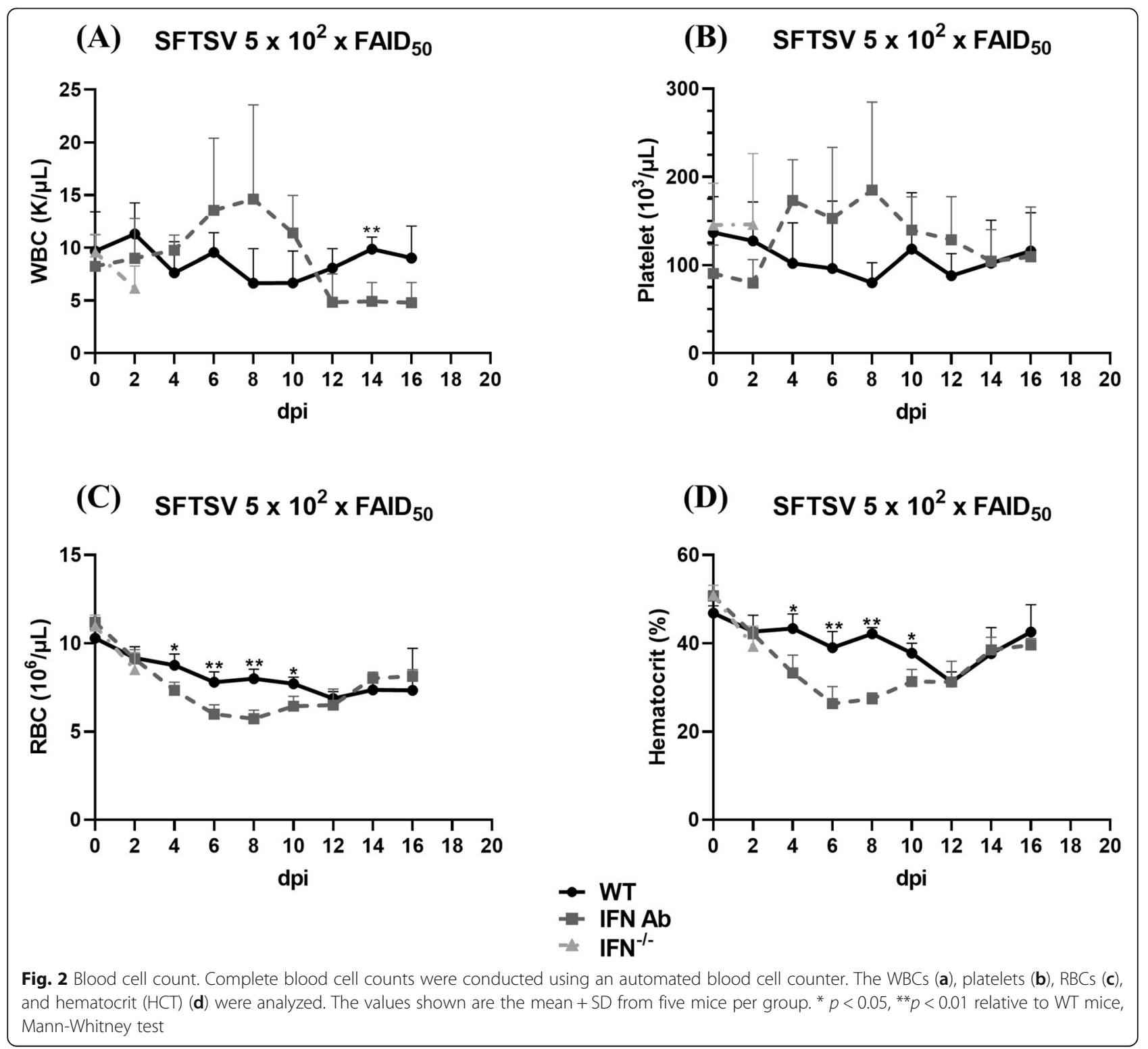




\section{SFTS viral load in various organs}

To study the pathogenesis of SFTSV, four mice of each $5 \times 10^{2}$ SFTSV-infected group were necropsied 1, 3, 7, 12 , and $17 \mathrm{dpi}$ and the viral load for each organ were evaluated. The SFTSV RNA in the tissues, including the brain, lung, liver, spleen, kidney, s. intestine, and 1. intestine, was analyzed by RT-PCR. At $1 \mathrm{dpi}$, SFTSV RNA was detected in all the tested organs, but there was no significant difference in viral copy number among the groups of mice (Fig. 3). However, 3 dpi, the IFNAR ${ }^{-/-}$ mice showed significantly higher $(p<0.05)$ SFTSV RNA levels in all organs than those of the other two groups of mice. The highest SFTSV RNA levels were detected in the spleen compared to the other organs of the IFNA $\mathrm{R}^{-/-}$mice. Similar SFTSV RNA viral levels were detected in all organs of the WT and IFNAR Ab mice. SFTSV RNA was not detected after $12 \mathrm{dpi}$ in the brain and lung, and after $17 \mathrm{dpi}$ in the liver, kidney, s. intestine, and 1. intestine of the WT and IFNAR Ab mice. In the serum samples, the IFNAR ${ }^{-/}$mice showed significantly higher SFTSV RNA than that of the IFNAR Ab mice 2 dpi. SFTSV RNA was detected consistently until 14 dpi in the WT and IFNAR Ab mice.

\section{SFTS viral RNA detection in mice excreta}

In mice infected with $5 \times 10^{2}$ FAID $_{50}$ SFTSV, eye and oral swabs, and urine and feces were collected 1, 3, 5, 7, $9,11,13,15$, and 17 dpi to evaluate viral antigen shedding and the viral load for each sample were evaluated. The WT mice showed no clinical symptoms at any day post-infection with SFTSV. However, SFTS viral RNA was detected in the eye and oral swabs, and urine and feces 5 dpi (Fig. 6). In the case of the IFNAR Ab and IFNAR $^{-1-}$ mice, SFTSV RNA was detected earlier than that of the WT mice in the eye and oral swabs, and urine (after $3 \mathrm{dpi}$ ), and the IFNAR Ab mice showed longer viral shedding than the WT mice (up to $7 \mathrm{dpi}$ ). These results showed that the SFTSV-infected mice could shed SFTS viral RNA, regardless of clinical symptoms, and SFTS viral RNA could be released for a longer time in mice with downregulated IFN signaling.

\section{Pathological examination}

To assess the progression of SFTSV over time, histopathology and IHC in each organ was examined in the necropsy tissues of four mice inoculated i.p with $5 \times 10^{2}$ FAID $_{50}$ SFTSV at 1, 3, 7, 12, and $17 \mathrm{dpi}$. The WT mice had no observable histological abnormalities. Between the two IFN signaling-regulated mice groups, lesions were observed sooner in the IFNAR ${ }^{-/-}$mice. At 3 dpi, coagulation necrosis in the liver and white pulp atrophy, especially in the marginal zone of the spleen of the IFNAR $^{-/-}$mice, were observed (Figs. 4a and 5a). At 7 dpi, coagulation necrosis and mononuclear inflammatory cell infiltration around the necrotic lesions of the liver and white pulp atrophy in the spleen of the IFNAR Ab mice were observed. Since one of the major clinical manifestations of SFTS is gastrointestinal symptoms and the SFTSV-infected IFNAR Ab and IFNAR ${ }^{-/}$mice showed gastrointestinal symptoms, we histopathologically evaluated the s. intestine and measured the villus/ crypt depth $(\mathrm{V} / \mathrm{C})$ ratio in the s. intestine. At least $20 \mathrm{~V} /$ $\mathrm{C}$ ratios were measured for each mouse in the proximal s. intestine. The WT mice had long, intact, regular villi at all time points, and the $\mathrm{V} / \mathrm{C}$ ratios did not differ significantly (Fig. 4b, c). However, the IFNAR Ab and IFNAR $^{-/-}$mice showed shortening, damaged, blunting villi, and the $\mathrm{V} / \mathrm{C}$ ratios significantly decreased from 3 dpi. All IFNAR ${ }^{-1-}$ mice succumbed to SFTSV at $3 \mathrm{dpi}$, but the surviving IFNAR Ab mice recovered villus morphology and $\mathrm{V} / \mathrm{C}$ ratio from $12 \mathrm{dpi}$ comparable to 1 dpi. In the present study, SFTS viral RNA was the most enriched in the spleen of all SFTSV-infected mice and previous studies suggested that the spleen may be the primary target organ of SFTSV [10, 19]. Therefore, we performed immunohistochemistry assays with spleen sections isolated $3 \mathrm{dpi}$ using a monoclonal antibody against SFTSV $N$ protein (NP). As shown in Fig. $5 b$, the frequency of SFTSV NP antigen-positive cells was in the order of IFNAR ${ }^{-/-}$, IFNAR Ab, and WT mice, consistent with the qPCR results of this study. SFTSV NP antigenpositive cells were rarely detected in the white pulp but mainly detected in the marginal zone of the spleen, and were monocyte-like cells in all groups of mice.

\section{Discussion}

In this study, we intraperitoneally inoculated different titers of SFTSV into WT, IFNAR Ab, and IFNAR ${ }^{-1-}$ mice. Similar to previous studies, the no immunocompetent WT mice showed any clinical signs or died. However, the IFNAR $^{-/-}$mice succumbed to SFTSV within 3 dpi even at small titers of SFTSV $\left(5 \times 10^{2}\right.$ FAID $\left._{50}\right)$. Therefore, the IFNAR ${ }^{-/-}$mice might be not suitable to represent the clinical symptoms of human SFTSV infection. The IFNAR Ab mice showed similar survival rates after infection following inoculation with $5 \times 10^{5}$ to $5 \times 10^{3}$ FAID $_{50}$. However, in mice infected with $5 \times 10^{2}$ FAID $_{50}$ SFTSV, the IFNAR Ab mice survived and recovered from 7 dpi (Fig. 1a). These findings showed that immunocompetent mice could be infected with SFTSV by partially blocking type I IFN signaling. A previous study tried to make a mouse model that did not cause clinical symptoms in immunocompetent mice by injections of type 1 IFNAR Ab to mice infected with ZIKV [14]. The main symptom of ZIKV is related to central nervous system effects. However, the type I IFNAR Ab did not pass through the blood-brain barrier $(\mathrm{BBB})$, so the main symptoms of ZIKV infection were not recapitulated. But, 


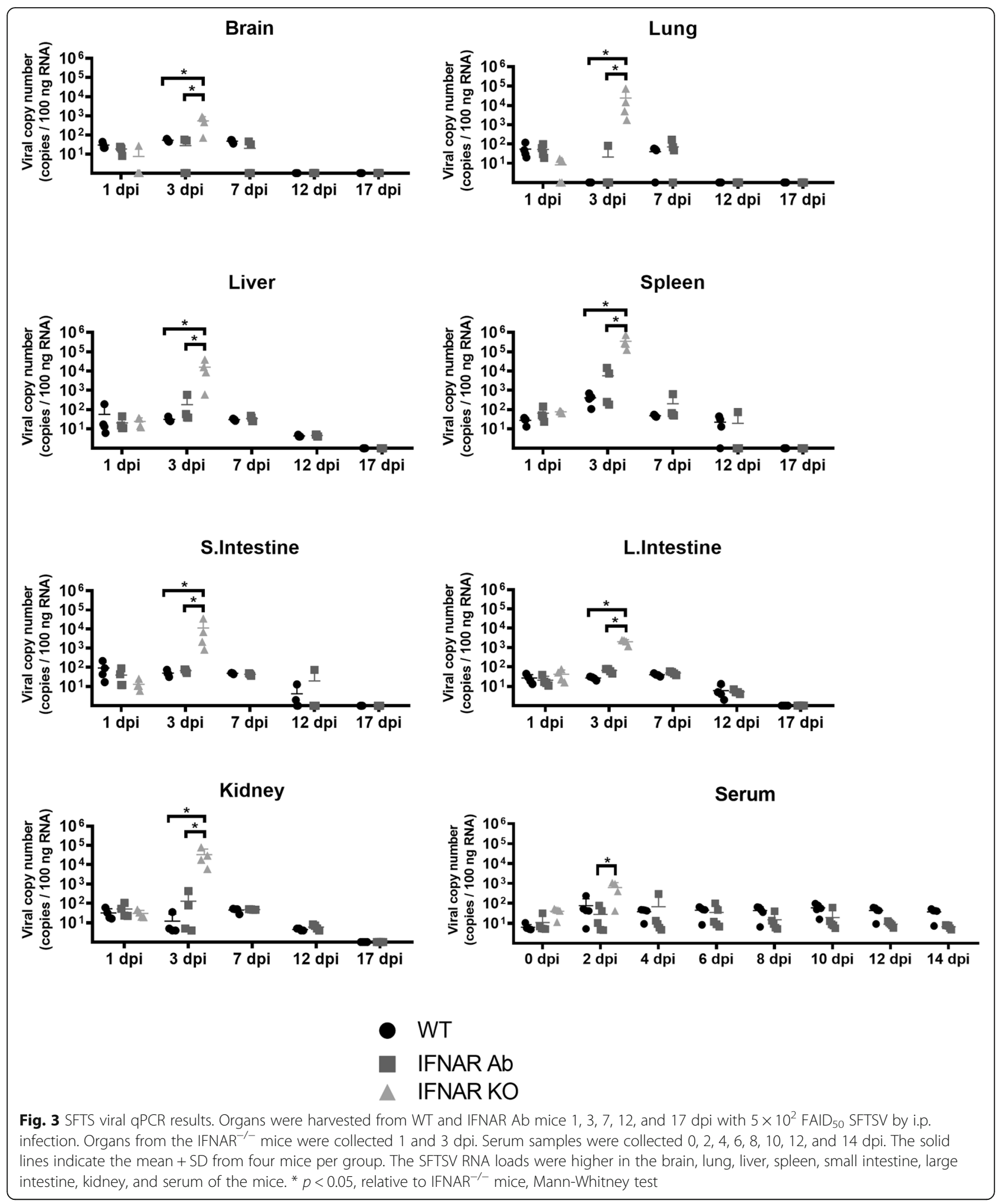

in the present study, the IFNAR Ab mice recapitulated the fatality of SFTSV infections because the main target of SFTSV is a parenchymal organ, such as the spleen. These findings suggest that transgenic mice can be used for SFTS studies after the administration of IFNAR Ab, allowing the study of various pathways involved in SFTSV infections. At present, the strongest candidate animal model of SFTSV infection might be aged ferrets 


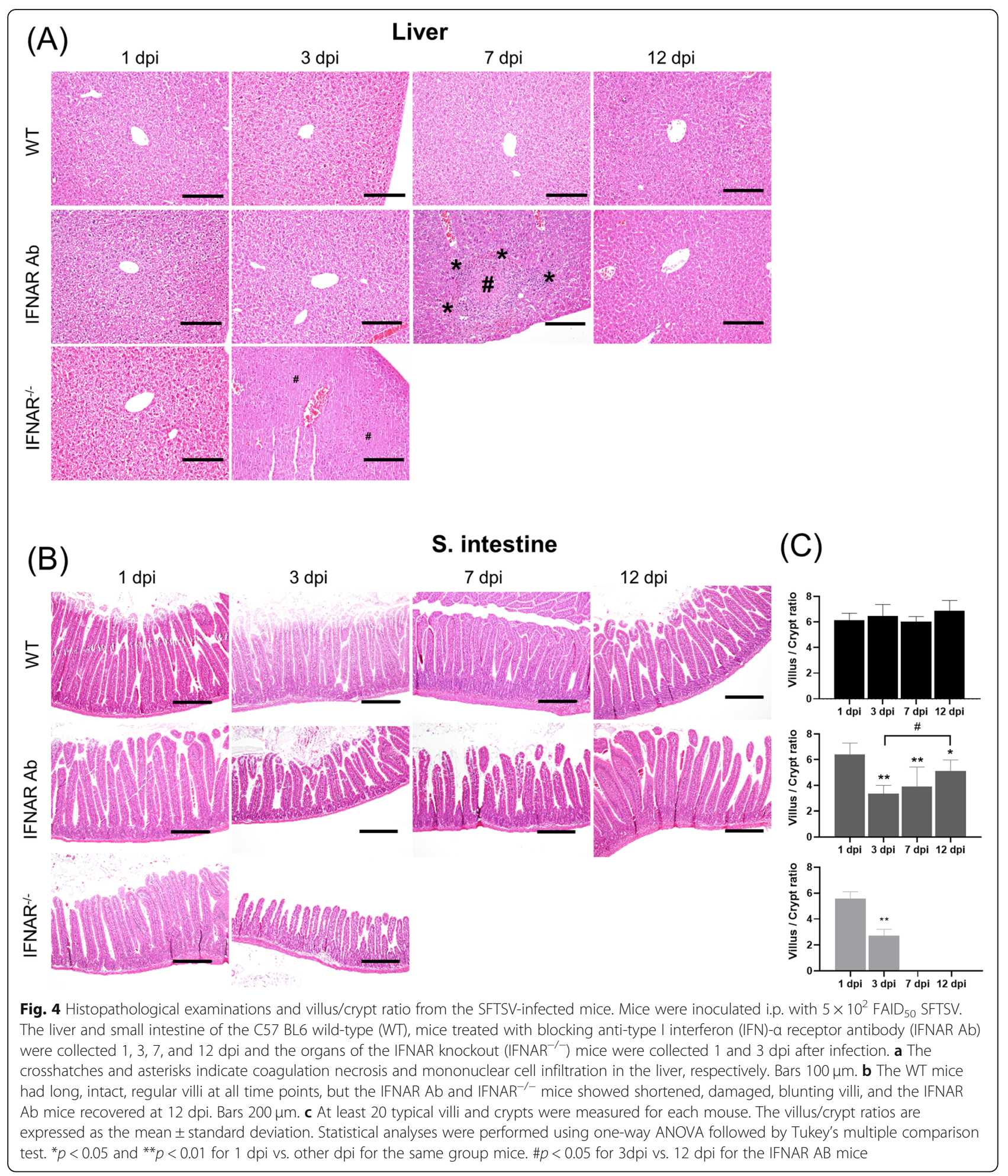

because they exhibit symptoms similar to humans. However, because aged ferrets are outbred and generally unavailable for commercial use, this model has limitations in studying the pathogenesis of SFTS [6].
In public health, the risk of infection from asymptomatic carriers has increased [20,21]. Although human-tohuman or cat-to-human SFTSV transmissions have been reported, the risk of infection from an asymptomatic 

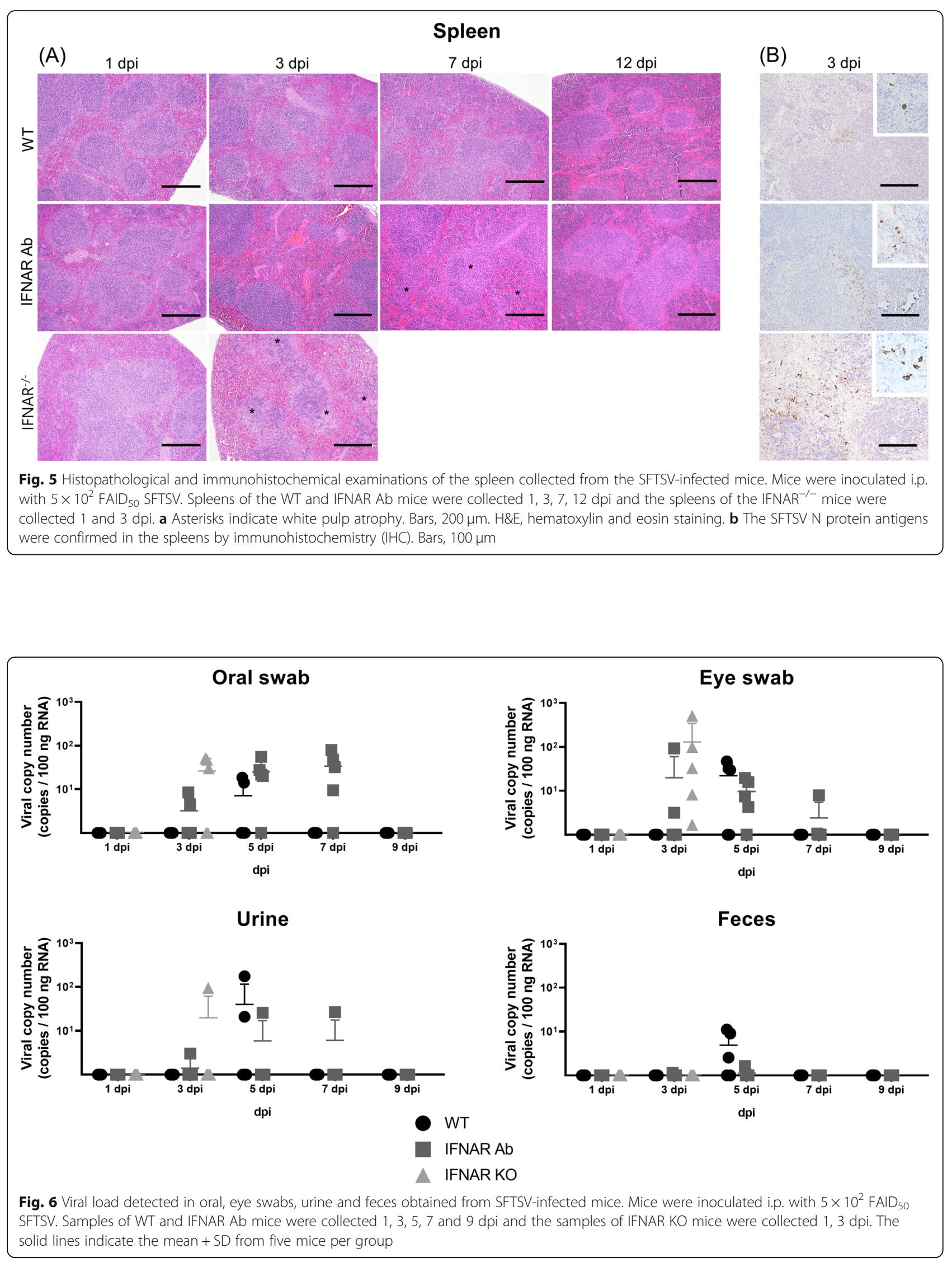
animal carrier of SFTSV has not been confirmed [22, 23]. In this study, we confirmed that immunocompetent, asymptomatic WT mice shed SFTS viral RNA 5 dpi through various excreta (Fig. 6). As expected, the IFNAR Ab mice, which showed clinical signs, shed SFTS viral RNA from 3 to $7 \mathrm{dpi}$. Since our system could only detect and measure SFTSV RNA, the infectious titers of SFTSV need to be determined in a future study. Furthermore, studies on whether asymptomatic carrier mice can infect other mice are needed.

A previous study suggested that SFTSV targeted macrophages, immature B cells, and reticular cells in the $\mathrm{IFNAR}^{-1-}$ mice [10]. The IHC results showed that SFTSV antigens were mainly detected in monocyte-like cells in the marginal zone of the white pulp of spleen, regardless of the group of mice (Fig. 5b). Marked marginal zone reduction in the spleen was the main difference between the dead IFNAR ${ }^{-/-}$and the surviving mice (Fig. 5a). The marginal zone has a key role in the antiviral response and especially, marginal zone metallophilic macrophages (MOMA) are important for initiating an antiviral B cell response [24]. Furthermore, deficiency in humoral responses and the disruption of B cell immunity affected fatal human SFTSV infection [25]. Based on these results, it is speculated that reductions in the marginal zone and MOMA might affect humoral response deficiency in the SFTSV-infected mice without IFN signaling. Therefore, it will be necessary to determine the mechanism of how IFN signaling deficiency affects humoral immunity after SFTSV infection.

Our findings showed that healthy asymptomatic mice could shed SFTSV via various excreta and the IFNAR $\mathrm{Ab}$ mice had some limitations in hematologic manifestation but recapitulated the fatality of SFTSV infections.

\section{Conclusions}

Regulation of type I IFN signaling by injecting type 1 IFNAR Ab into different types of immunocompromised mice will help to elucidate the pathogenesis of SFTSV infection with small quantities of virus.

\section{Abbreviations \\ SFTS: Severe fever with thrombocytopenia syndrome; SFTSV: SFTS virus; WT: Wild-type; IFN: Interferon; IFNAR Ab: IFN-a receptor antibody; IFNA $\mathrm{R}^{-/-}$: IFNAR knockout; dpi: Days post-infection; ZIKV: Zika virus; FBS: Fetal bovine serum; FAID 50 : Fluorescence active infectious dose; MAb: Monoclonal antibody; PBS: Phosphate-buffered saline; RT-PCR: Real-time PCR; s. intestine: Small intestine; I. intestine: Large intestine; H\&E: Hematoxylin and eosin; WBC: White blood cell; V/C ratio: Villus/crypt depth; NP: N protein; BBB: Blood-brain barrier; MOMA: Marginal zone metallophilic macrophages}

\section{Authors' contributions}

SC Park, JY Choi participated in design of the experiments, performed the experiments, analyzed the data, and drafted the manuscript. JY Park and SG Lee performed and supported the experiments. SK Eo, JK Oem, DS Tark, M You and DH Yu edited and revised manuscript. B Kim is responsible for the final approval of the manuscript.

\section{Funding}

The research was supported by the Republic of Korea (Government-wide R\&D Fund project for infectious disease research (GFID), HG18C0084).

Availability of data and materials

Not applicable.

\section{Competing interests}

The authors have no conflict of interest to report.

\section{Author details}

${ }^{1}$ College of Veterinary Medicine, Jeonbuk National University, Iksan 54596, Republic of Korea. ${ }^{2}$ Korea Zoonosis Research Institute, Jeonbuk National University, Iksan 54531, Republic of Korea. ${ }^{3}$ College of Veterinary Medicine, Gyeongsang National University, Jinju 52828, Republic of Korea. ${ }^{4}$ Laboratory of Veterinary Internal Medicine, BK21 PLUS Program for Creative Veterinary Science Research, Research Institute for Veterinary Science and College of Veterinary Medicine, Seoul National University, 1 Gwanak-ro, Gwanak-gu, Seoul 08826, Republic of Korea.

Received: 27 July 2020 Accepted: 11 October 2020

Published online: 21 October 2020

\section{References}

1. Heo D-H, Kang YM, Song K-H, Seo J-W, Kim J-H, Chun JY, et al. Clinical score system to differentiate severe fever with thrombocytopenia syndrome patients from patients with scrub typhus or hemorrhagic fever with renal syndrome in Korea. J Korean Med Sci. 2020;35:e77.

2. Lin T-L, Ou S-C, Maeda K, Shimoda H, Chan JP-W, Tu W-C, et al. The first discovery of severe fever with thrombocytopenia syndrome virus in Taiwan. Emerg Microbes Infect. 2020;9(1):148-51.

3. Takayama-Ito M, Saijo M. Antiviral drugs against severe fever with thrombocytopenia syndrome virus infection. Front Microbiol. 2020;11:150.

4. Mehand MS, Al-Shorbaji F, Millett P, Murgue B. The WHO R\&D blueprint: 2018 review of emerging infectious diseases requiring urgent research and development efforts. Antivir Res. 2018;159:63-7.

5. Jin $C$, Jiang $H$, Liang $M$, Han $Y$, Gu W, Zhang $F$, et al. SFTS virus infection in nonhuman primates. J Infect Dis. 2015;211(6):915-25

6. Park SJ, Kim Yl, Park A, Kwon HI, Kim EH, Si YJ, et al. Ferret animal model of severe fever with thrombocytopenia syndrome phlebovirus for human lethal infection and pathogenesis. Nat Microbiol. 2019;4(3):438-46.

7. Park ES, Shimojima M, Nagata N, Ami Y, Yoshikawa T, Iwata-Yoshikawa N, et al. Severe fever with thrombocytopenia syndrome phlebovirus causes lethal viral hemorrhagic fever in cats. Sci Rep. 2019;9(1):1-18.

8. Wang BX, Fish EN. Global virus outbreaks: interferons as 1st responders. Semin Immunol. 2019:43:101300.

9. Liu Y, Wu B, Paessler S, Walker DH, Tesh RB, Yu X-J. The pathogenesis of severe fever with thrombocytopenia syndrome virus infection in alpha/beta interferon knockout mice: insights into the pathologic mechanisms of a new viral hemorrhagic fever. J Virol. 2014;88(3):1781-6.

10. Matsuno K, Orba Y, Maede-White K, Scott D, Feldmann F, Liang M, et al. Animal models of emerging tick-borne phleboviruses: determining target cells in a lethal model of SFTSV infection. Front Microbiol. 2017:8:104.

11. Tani H, Fukuma A, Fukushi S, Taniguchi S, Yoshikawa T, Iwata-Yoshikawa N, et al. Efficacy of T-705 (Favipiravir) in the treatment of infections with lethal severe fever with thrombocytopenia syndrome virus. mSphere. 2016;1(1): e00061-15.

12. Gowen BB, Westover JB, Miao J, Van Wettere AJ, Rigas JD, Hickerson BT, et al. Modeling severe fever with thrombocytopenia syndrome virus infection in golden syrian hamsters: importance of STAT2 in preventing disease and effective treatment with favipiravir. J Virol. 2017;91(3): e01942-16.

13. Kitagawa $Y$, Sakai M, Shimojima M, Saijo M, Itoh M, Gotoh B. Nonstructural protein of severe fever with thrombocytopenia syndrome phlebovirus targets STAT2 and not STAT1 to inhibit type I interferon-stimulated JAKSTAT signaling. Microbes Infect. 2018;20(6):360-8.

14. Lazear Helen M, Govero J, Smith Amber M, Platt Derek J, Fernandez E, Miner Jonathan J, et al. A mouse model of zika virus pathogenesis. Cell Host Microbe. 2016;19(5):720-30.

15. Lorenzo G, Martin-Folgar R, Hevia E, Boshra H, Brun A. Protection against lethal Rift Valley fever virus (RVFV) infection in transgenic IFNA 
$\mathrm{R}(-/-)$ mice induced by different DNA vaccination regimens. Vaccine. 2010;28(17):2937-44.

16. Lee SY, Kang JG, Jeong HS, Kim WM, Son KD, Kim JS, et al. Complete genome sequences of two severe fever with thrombocytopenia syndrome virus strains isolated from a human and a dog in the Republic Of Korea. Microbiol Resour Announc. 2019;8(31):e01695-18.

17. Yoshikawa T, Fukushi S, Tani H, Fukuma A, Taniguchi S, Toda S, et al. Sensitive and specific PCR systems for detection of both Chinese and Japanese severe fever with thrombocytopenia syndrome virus strains and prediction of patient survival based on viral load. J Clin Microbiol. 2014; 52(9):3325-33.

18. Pinto AK, Daffis S, Brien JD, Gainey MD, Yokoyama WM, Sheehan KCF, et al. A temporal role of type I interferon signaling in CD8+ T cell maturation during acute West Nile virus infection. PLoS Pathog. 2011;7(12):e1002407.

19. Jin C, Liang M, Ning J, Gu W, Jiang H, Wu W, et al. Pathogenesis of emerging severe fever with thrombocytopenia syndrome virus in C57/BL6 mouse model. Proc Natl Acad Sci U S A. 2012;109(25):10053-8.

20. Patrozou E, Mermel LA. Does influenza transmission occur from asymptomatic infection or prior to symptom onset? Public Health Rep. 2009;124(2):193-6.

21. Shao P, Shan Y. Beware of asymptomatic transmission: study on 2019-nCoV prevention and control measures based on extended SEIR model. bioRxiv. 2020; 2020.01.28.923169.

22. Jung IY, Choi W, Kim J, Wang E, Park SW, Lee WJ, et al. Nosocomial personto-person transmission of severe fever with thrombocytopenia syndrome. Clin Microbiol Infect. 2019;25(5):633.

23. Kida K, Matsuoka Y, Shimoda T, Matsuoka H, Yamada H, Saito T, et al. A case of cat-to-human transmission of severe fever with thrombocytopenia syndrome virus. Jpn J Infect Dis. 2019;72(5):356-8.

24. Matter MS, Hilmenyuk T, Claus C, Marone R, Schürch C, Tinguely M, et al. Destruction of lymphoid organ architecture and hepatitis caused by CD4+ T cells. PLoS ONE. 2011;6(9):e24772.

25. Song P, Zheng N, Liu Y, Tian C, Wu X, Ma X, et al. Deficient humoral responses and disrupted B-cell immunity are associated with fatal SFTSV infection. Nat Commun. 2018;9(1):1-15.

\section{Publisher's Note}

Springer Nature remains neutral with regard to jurisdictional claims in published maps and institutional affiliations.

Ready to submit your research? Choose BMC and benefit from:

- fast, convenient online submission

- thorough peer review by experienced researchers in your field

- rapid publication on acceptance

- support for research data, including large and complex data types

- gold Open Access which fosters wider collaboration and increased citations

- maximum visibility for your research: over $100 \mathrm{M}$ website views per year

At $\mathrm{BMC}$, research is always in progress.

Learn more biomedcentral.com/submissions 